\title{
OCCUPATIONAL TRAINING IN HIGH SCHOOL: WHEN DOES IT PAY OFF ?
}

\author{
John Bishop \\ Cornell University \\ Working Paper \# 88-09 \\ New York State School of Industrial and Labor Relations \\ Cornell University \\ Ithaca, New York 14851-0925 \\ 607-255-2742 \\ Former Associate Director: Research \\ The National Center for Research in Vocational Education
}

The research that has culminated in this paper was sponsored by the National Center for Research in Vocational Education, Research for Better Schools, Inc. and the National Assessment of Vocational Education all funded in one way or another by the office of Research for Educational Improvement and the Department of Education. I would like to thank William Firestone, Joan Buttram, Ellen Newcombe, Paul Campbell, Lamry Hotchkiss, Robert Meyer and Mac MacCaslin for helpful comments on earlier versions of the paper. Points of view and opinions expressed are personal and do not necessarily represent the position of Cornell University, The National Center for Research in Vocational Education or Research for Better Schools. 
OCCUPATIONAL TRAINING IN HIGH SCHOOL: WHEN DOES IT PAY OFF ?

\begin{abstract}
About half of all youth either do not complete high school or end their formal education with the high school diploma. Even higher proportions of minority, disadvantaged and handicapped youth do not enter postsecondary education. Should public schools offer these youth occupationally specific education and training? If so, what form should this education take? Should the goal of the occupational component of high school vocational education be occupationally specific skills, career awareness, basic skills or something else? What should be the relationship between programs providing occupationally specific training and the employers who hire their graduates?

In addressing these issues it is important to know how taking occupationally specific courses influences dropout rates, probabilities of employment, wage levels, productivity, access to additional education and training, job satisfaction, basic skills, citizenship, and other positive traits of character. It is also important to understand the relative effectiveness of alternate vocational education programs in achieving these goals. The first part of the paper is a review of what current research tells us about these issues. The review is organized around 7 questions. The questions and the corresponding findings are listed below:

\section{Questions and Answers}

1. How large are the economic benefits of occupationally specific education and what causes them?

(A) Bconomic benefits are zero if a training related job is not obtained. If a training related job is obtained, monthly earnings are 7-86 greater, unemployment is substantially reduced, labor force participetion is more consistent, and productivity on the job is increased.

2. To what extent are the occupationally specific skills learned in high school being used?

(A) Less than half get training related jobs (rigorously defined).

3. Why are the occupationally specific skills learned of ten not used on a job?

(A) Lack of emphasis on placement, insufficient involvement of employers, training for jobs not in demand.

4. Does vocational education generate non-economic benefits? 
(A) There is no evidence that it either increases or decreases non-economic benefits relative to a general curriculum.

5. Does vocational education lower dropout rates?

(A) Yes. Taking one voc ed course each year raises the high school graduation rate by 6 percentage points and this raises expected earnings by about 2 percent.

6. Can basic skills substitute for occupational skills?

(A) No, jobs require both.

7. Have high rates of skill obsolescence drastically lowered the payoff to occupationally specific training?

(A) No. Obsolescence is less important than the risk of not using and forgetting skills.

The research clearly implies that occupationally specific education has a very positive impact on labor market success when training related jobs are obtained. If jobs are not related to training, high school graduates receive no economic or noneconomic benefits from their vocational education. The productivity enhancing effects of vocational education also occur only when the job occupied is related to the training. Taking vocational eduction courses lowers the dropout rate of students at risk of dropping out, but even here it's holding power probably derives largely from the student's hope that occupational studies will improve the jobs he/she can get. Unfortunately, less than one-half of the graduates of high school vocational programs who did not go to college, work in occupations that match (very broadly defined) their training. Training related placement rates vary greatly from program to program and much of the variation can be explained by features of the vocational education program. A very important program feature is vocational teachers (not placement directors) taking responsibility for and devoting time to the placement of their students.

It is also important that a well informed career choice precede entry into intensive occupational training, that training be offered only in occupations with substantial employer demand, and with substantial employer involvement in delivery of the training. Finally it is recommended that state aid for vocational education be allocated by a formula that rewards success in serving students, rather than just success in recruiting them and that offers greater rewards for success with more challenging students. 


\section{PART I REVIEW OF RESEARCH}

\section{How Large are the Economic Benefits of Vocational} Education and What Causes Them?

\section{Students Benefits of High School Vocational Education}

The effect of high school vocational education on wage rates and earnings has been extensively studied in the last decade. The consensus of the research is that for women commercial training has substantial positive effects on the earnings, but technical and home economics training has either zero or negative effects on earnings (Grasso and Shea, 1979; Meyer, 1982; Gustman and Steimeier, 1981). For men the results are less favorable. Campbell, et al. (1986) summarized the literature by saying "The evidence is mixed as to whether male vocationally educated high school graduates (especially white men) earn significantly more per hour or per week than otherwise similar nonvocational graduates" (p. 13). The National Commission for Employment Policy (1981) concluded that "most studies based on nationally representative samples of students could not find convincing evidence of positive labor market effects of secondary vocational education on males, compared to alternative uses of student's timen (p. 15).

Recent research by Campbell, et al. (1986) and Daymont and Rumberger (1982) have discovered why the overall impact of vocational education is of ten so small. For graduates who use the training on their job, these two studies demonstrate that vocational education has large positive effects on the earnings of both men and women. The reason overall impacts are so small is that the majority of vocational graduates do not get training related jobs. Table 1 summarizes Campbell, et al's analysis of data on both males and females from two nationally representative longitudinal surveys (High School and Beyond and the National Longitudinal Survey) where participation in vocational education can be defined by reference to high school transcripts rather than student self reports. Vocational graduates who obtain a job in an occupation matching their field of training spend about 20 percent more time in the labor force than general track graduates. ${ }^{2}$ Their rates of unemployment are about 3 percentage points lower. Vocational graduates working outside their field of training are not significantly more likely to be in the labor force or to be employed than general track graduates. 
The third and fourth columns of the table present estimates of the effect of vocational education on current monthly earnings controlling for current and past enrollment in college. High school graduates who took a vocational concentration obtain significantly higher monthly earnings ( 7 to 8 percent higher) only when their current job is related to their training. When their current job is not related to their training, they do not receive higher wage rates than students who have pursued a general program of study in high school. ${ }^{2}$ Students who pursued an academic curriculum in high school did not do better than those pursuing a general curriculum; in one data set they were earning $5 \%$ less.

If students stay in the occupation for which they train for many years the benefits of the occupational training appear to grow even larger. An analysis of data from the NLS reported in Campbell et al (1987) found that graduates of vocational programs who spent 808 of their work time since high school in a training related job earned 41 percent more in 1984 than the vocational graduates who had never had a training related job.

\section{Effects on Productivity and Training Costs}

Workers with 12 or fewer years of schooling account for the bulk of the nation's blue collar, sales, clerical and service workers. The training requirements and intellectual demands of many of these jobs are quite considerable. In clerical jobs, for instance, the time and resources devoted to training a new employee during the first 3 months on a job has a value equal to 45 percent of the output of a worker with 2 years of tenure at the firm. Training costs during the first 3 months are 36 percent of an experienced worker's potential output for retail sales jobs, 38 percent for blue collar jobs and 25 percent for service jobs (Bishop, 1985). Presumably the graduates of vocational programs are more productive workers and require less training. How large are these effects?

Studies of this issue find that vocationally trained workers are somewhat more productive and less costly to train than other workers doing the same job but only when the job is related to their training. The evidence for this statement comes from statistical comparisons of two workers doing the same job. ${ }^{3}$ The data are presented in table 2, which has been summarized from Bishop (1982). Compared to those without vocational training, new hires 


\begin{tabular}{|c|c|c|c|c|}
\hline $\begin{array}{l}\text { roups In Comparison } \\
\text { o General Curriculum }\end{array}$ & $\begin{array}{l}\text { Labor Force } \\
\text { Participation } \\
\text { (age 20) }\end{array}$ & $\begin{array}{l}\text { IInemp loyment } \\
\text { (aqe } 20)\end{array}$ & $\begin{array}{l}\text { Monthly } \\
\text { Farnings } \\
\text { (age ?0) }\end{array}$ & $\begin{array}{l}\text { Monthly } \\
\text { Earninas } \\
\text { (age 19-26) }\end{array}$ \\
\hline Vocational Grads & & & & 1985 \\
\hline Training Related & $20 \% * *$ & -3 & $7 \% * *$ & $8 \% * *$ \\
\hline Not Training Related & $2 \%$ & 1 & $3 \% *$ & $-5 \%$ \\
\hline Academic Grads & $-9 \% * * *$ & 1 & $-5 \%$ & $0 \%$ \\
\hline \multicolumn{5}{|c|}{ 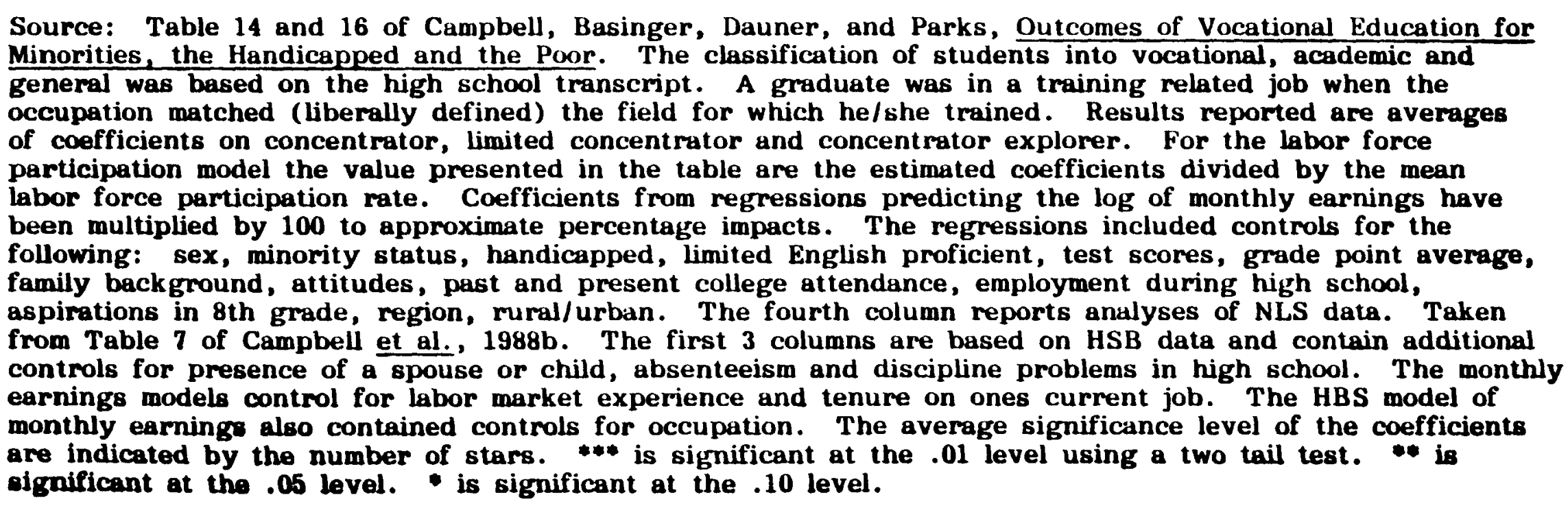 } \\
\hline
\end{tabular}




\section{TABLE 2}

IMPACT OF VOCATIONAL EDUCATION

ON TRAINING COSTS AND PRODUCTIVITY

(Percentage Difference Fram Mentbers

Without Vocational Training)

RECEIVED VOCATIONAL TRAINING IN A SCHOOL

OUTCMES

oft Time
Relevant to Job

$-7.3 \%$
Not Relevant to Job

\section{Productivity}

in first 2 weeks

$8.6 \% * *$

$-3.0 \%$

in next 10 weeks

$6.1 \% * *$

$-.5 \%$

At present or when

the employee separated

$6.6 \% * * *$

$1.4 \%$

**Impact of relevant vocational education is significantly larger than the impact of non-relevant vocational education at the .05 level (two-tail test)

t**Impact of relevant vocational education 18 significantly higher at the .01 level (two-tall test)

Source: Table 5 of B1shop The Social Payoff from Occupationally Specific Training. H1gh school vocational graduates account for only about 30 percent of the vocationally trained workers in the sample. Most of the rest recelved their training at a 2-year postsecondary institution. 
who have received school provided vocational training that is relevant to their job require 7.3 percent more training during the first 3 months on the job. Those with relevant training were 8.6 percent more productive in the first two weeks, and 6.1 percent more productive during the next 10 weeks and 6.6 percent more productive after a year or so at the firm. Those with non-relevant vocational training were less productive initially and insignificantly 1.4 percent more productive after a year at the firm.

These findings imply that the private and social benefits of vocational education derive from the occupationally specific skills that are developed. Some of the skills taught in vocational classes are transferable--useful in a great variety of occupations--but skills taught in nonvocational classes are transferable as well. Vocational classes are not better at instilling valuable transferable skills than nonvocational classes. In other words, vocational education as now practiced does not do a better job of preparing youth for generic jobs than more academic forms of education. There may be ways of delivering vocational education that do a better job of teaching character or generic skills than an academic education but these programs are not common enough to affect statistics on the aggregate impact of vocational education.

2. To What Extent are the Occupationally Specific Skills Learned in High School Being Used?

During their four years in high school, 1982 graduates took an average 2.3 Carnegie units of exploratory vocational courses (industrial arts, home economics, typing I, etc.), 2.1 units of occupational vocational courses and 17.2 units of other courses. The twenty-seven percent of these graduates who described themselves as specializing in a vocational field, obtained 2.8 units in exploratory vocational courses, 3.7 Carnegie units in occupational vocational and 14.9 units in other areas (Pliski, 1984; table 3.3). This implies that the 73 percent of students who report they are not specializing in a vocational field account for 67 percent of the students in exploratory courses and 52 percent of the students in occupational courses.

How frequently do students use and therefore benefit from their occupationally specific training? Twenty-eight percent of the graduates who have taken 2 or more occupational vocational courses in a specific area 
(the concentrators, limited concentrators and concentrator explorers of the typology developed in Campbell, Orth, and Seitz, 1981) enter a four-year college or university after high school (unpublished tabulation of 1983 NLS youth provided by Paul Campbell). It is not clear how many of these graduates major in subjects which make use of knowledge and skills obtained in rocational courses.

What about the students who seek jobs immediately after graduating from high school? The empirical work reported in the previous section classified a youth as having a training related job when the occupation of the individual's current or most recent job matched his/her field of training. By this definition, 43 percent of the employed graduates who had been out of school between one and ten years currently had a training related job (broadly defined) in the 1985 National Longitudinal Survey of Youth (Campbell et al., 1987a). Other studies using the same methodology obtain similar results. * Felstehausen's (1973) study of 1981 vocational graduates in the State of Illinois found training related placement rates of 27 percent in business occupations, 17 percent in trade and industry, 52 percent in health and 20 percent in agriculture. Conroy and Diamond's study (1976) of Massachusetts graduates obtained a training related placement rate of 29 percent for business and 37 percent for trades and industry. In contrast, 6 months after passing a German apprenticeship examination, 68 percent of those with civilian jobs were employed in the occupation for which they were trained (much more narrowly defined) (the Federal Institute for Vocational Training, 1986).

3. Why Are The Occupationally Specific Skills Learned So Seldom Used On A Job?

In 1980 the National Center for Research in Vocational Education undertook a massive study of the determinants of training related placement rates (McKinney et al., 1982; Lewis et al., 1982). Controlling for the local unemployment rate and the congruence of school and community racial composition, Lewis et al. (1982) found that training related placement rates were higher when vocational teachers accepted responsibility for placement, when they spent considerable time on placement, when admission to the program was restricted and when career exploration was an important part of the program. 
Other research suggests that another important cause of the problem is the limited employer involvement in the training. Mangum and Ball (1986) have found in their analyses of NLS data that employer controlled training institutions have much higher training related placement rates. Using a procedure of matching training fields against jobs, they found that the proportion of male graduates who had at least one job in a related field was 85 percent for company training, 71 percent for apprenticeship, 52 percent for vocational-technical institutes, 22 percent for proprietary business colleges and 47 percent for military trainees who completed their tour of duty. The rates for females were 82 percent for company training, 59 percent for nursing schools, 61 percent for vocational-technical institutes, 55 percent for proprietary business colleges and 49 percent for military training.

The graduates who do not find training related jobs often complained that no such jobs were available. Aggregating the data from 3 different follow up studies, Mertens et al. (1980) report that 25 percent said no job was available in an area related to training, 11 percent said their high school training was insufficient and 10 percent said they couldn't earn enough money in a related field. These statistics suggest that occupational training needs to be sensitive to the market both in the selection of and design of training programs.

Poor career guidance is apparently contributing to the problem for 21 percent said they left the field because they didn't like the work, another 2 percent said they didn't know what the job was really like and 5 percent said they switched fields when they got training in the military or at a postsecondary institution.

Some of the students apparently take occupational courses without having real plans to pursue a related occupation. Counselors and vocational teachers report that some of the students taking vocational courses are there to avoid more difficult academic subjects or to get permission to take a job during part of the school day. Others apparently changed their career goals. Still others use the courses as a vehicle for career exploration (something for which they are often not really designed). 


\section{Does Vocational Education Generate Noneconomic Benefits?}

Some of the leading experts on vocational education argue that occupationally specific training is really intended to achieve a much broader purpose than preparation for a specific cluster of occupations. Harry Silberman, (1982), for instance, feels the primary purpose of secondary vocational education is:

"to promote full human development through exposure of the learner to work experience as part of the education process . . . . The purpose of the work is to further the education of the student; the work is subordinate to the education process; it is work for education" (p. 299)

If this goal were being achieved, we would expect (a) students to benefit from their vocational education regardless of whether they find a job in the field for which they are trained and (b) vocational students to receive noneconomic as well as economic benefits from their education. However, we have seen in section 1 that sadly, the students who take occupational courses and the employers who hire them do not benefit economically when students take jobs unrelated to the occupation for which training was received.

What about non-economic outcomes such as participation in organizations, political involvement and job satisfaction? Campbell, Mertens, Seitz and Cox, (1982) found that neither taking vocational courses nor finding a training related job appeared to have a significant impact on job satisfaction. Campbell and Basinger, (1985) found that vocational students were less likely to participate in most types of school and non-school youth organizations than students in the general curriculum. After graduating they were also 6 percentage points less likely to register to vote, 9.5 percentage points less likely to have voted in the last 3 years and 2.8 percentage points (10.1 rather than 12.9 percent) less likely to engage in a political activity such as making a campaign contribution. The lower rates of political participation of vocational graduates appear to be due to their social background, not the vocational program. When controls are entered for years of schooling and social background, high school vocational education appears to have no unique effect on political participation. It also appears to have no significant effects on views regarding whether women should work. 
Until new evidence is uncovered which contradicts these findings, the case for vocational education should probably rest on its ability to improve the employability and productivity of its students and to retain them in school.

\section{Does Vocational Education Lower the Dropout Rate?}

The second way occupationally specific education may be benefiting students is by persuading them to stay in school long enough to graduate. A high school diploma raises earning power by nearly 40 percent, so students who have been induced to stay in school benefit even if they earn no more than graduates of a general program.

It is very difficult, however, to determine whether vocational education lowers the dropout rate because students who are at higher risk of dropping out and dislike academic subjects tend to be attracted to the program. This means that vocational education's effects on retention cannot be measured without thoroughly controlling for grades, academic ability, alienation from school and a host of other background characteristics.

Using a longitudinal data set which contained controls for many of these variables, Mertens, Seitz and Cox, (1982) found that taking and passing a vocational course in 9 th grade significantly lowered the dropout rate of dropout prone youngsters during 10th grade (from about 9 to 6 percent). taking one vocational course during each of the 3 preceding years lowered the 12 th grade dropout rate from about 20 to 14 percent. The dropout rate during the 11th grade was not affected by taking vocational education in 10th grade. These results imply that consistently taking and passing one vocational course each year from 9th through 11th grade raises the high school completion rate of dropout prone youngsters from about 64 to 70 percent. Applying the average effect of obtaining a diploma, this raises expected earnings by approximately 2 percent. The equations predict that two vocational courses per year for 4 years would have raised the completion rate to about 76 percent and expected earnings by 4 percent.

\section{Can Basic Skills Substitute for Occupational Skills?}

If choices have to be made, what priority should be given to besic skills and what priority should be given to occupational skills? Basic skills-the ability to read, write, speak, compute and reason--are essential to almost 
everything a person does. Occupational skills are useful primarily at work and only when there is a correspondence between one's occupational skills and one's job. This suggests that occupationally specific training should occur after a career has been at least tentatively selected. Can one postpone career choice until graduation? Would it be feasible to concentrate solely on basic skills expecting that they would substitute for occupetional skills when a career is later selected?

A review of research by industrial psychologists on the relationship between productivity in particular jobs and various predictors of that productivity is helpful in thinking about this issue. This research has found that direct measures of both basic skills (general mental ability tests) and occupational skills (job knowledge tests) have very large associations with reported productivity (Hunter and Hunter, 1984) and Reilly and Chao, (1983).7 General mental ability (GMA) tests (such as the Armed forces Qualification Test, the Scholastic Achievement Test and components of the Employment Service's General Aptitude Test Battery) focus on verbal, quantitative, spatial, and reasoning abilities. Thus, they test many of the competencies that are the prime objectives of schooling. School attendance has been shown to improve performance on these tests (Lorge, 1945). Increases in the quality and quantity of education were probably responsible for the increase between World War I and World War II of .79 standard deviations in the average test scores of army draftees (the equivalent of 12 points on an IQ test).

The ability of GMA tests to predict job performance is greatest in jobs that are intellectually demanding. Many of the jobs that students enter after completing high school make considerable demands on what has come to be called basic skills, for GMA test validities are quite high for clerical workers (.54), for service workers (.48), skilled trades and crafts (.46), for protective service workers (.42) and even for semi-skilled factory jobs (.37). A validity of .54 implies that a one standard deviation difference in true ability is associated with .54 of a standard deviation difference in true performance. Since the standard deviation of worker productivity in clerical and semiskilled blue collar jobs is about 20 percent of average productivity (Schmidt and Hunter, 1983), we can estimate that the effect of one standard deviation impravement in "basic skills" is associated with 
an 11 percent improvement in productivity for clerical jobs, and an 8 percent improvement for semi-skilled factory jobs.

When, however, job knowledge (occupational skills) tests appropriate for the job compete with GMA (basic skills) tests in predicting job performance measured either by supervisory ratings or actual work samples, the job knowledge tests have the greatest impact (Hunter, 1983). When GMA is held constant, a one standard deviation improvement in job knowledge raises productivity by about 10 percent (when the standard deviation of output is 20 percent of the mean). When job knowledge is held constant, a one standard deviation improvement in GMA raises productivity by about 5 percent. Large improvements in job knowledge are easier to achieve than equivalent (in proportions of a standard deviation) improvements in basic skills. Thus while basic skills are important, there would seem also to be an important role for occupationally specific training. The research suggests that because basic skills and GMA have high associations with productivity primarily because they help the worker learn the job and occupation specific skills that are used to do the job.

From this evidence one is forced to conclude that basic skills are not a substitute for skills that are specific to a job or an occupation. Studies that have examined the influence of basic and occupational skills on job performance find that occupational skills have a larger direct impact on productivity than basic skills. Basic skills and occupational skills are both essential. Occupational skills and knowledge are essential because of their large direct effects on productivity. Basic skills are important partly because they also contribute to productivity directly but primarily because they aid the learning of job specific and occupational skills.

7. Have High Rates of Skill Obsolescence Drastically Lowered the Return to Occupationally Specific Training?

It is sometimes argued that high school students should concentrate on basic skills rather than occupational skills because jobs are changing so rapidly that occupational skills learned in school soon become obsolescent. This argument is sometimes preceded by the assertion: "In the future, technological advances will come at an increasingly fast pece" (Levin and Rumberger, 1983, p. 21). In fact, however, the available evidence on changing skill requirements suggests that change is less rapid now than in the past. 
Rates of job tumover, rates of exit from agriculture and overall technological progress are all lower now than in the first seven decades of the twentieth century. Separation rates in manufacturing were 5 percent per month during the 1920's and 4.4 percent during the 1970's. To be sure, the 1982 recession and the overvalued dollar have increased the number of workers being forced to change jobs and occupations. But the changes being experienced by the current generation of working adults pale by comparison to the changes experienced by the generation that lived through the depression, the mobilization for WWII and the rapid demobilization after the war. Workers have always had to learn new occupational skills.

The skill obsolescence argument against locating occupationally specific training in high schools has a number of flaws. First, obsolescence is a pervasive phenomenon. The ability to do square roots and long division by hand or on a slide rule has lost much of its value as the use of calculators has grown. Protons, electrons and neutrons are no longer considered the fundamental particles of nature. Rates of obsolescence are higher in fast changing fields and close to the frontier of knowledge. The labor market responds to high rates of skill obsolescence by paying a higher premium for the skill. The high starting salaries of engineers in part derives from the high rate of obsolescence of their skills. Consequently, there is no reason to expect a negative correlation between rates of skill obsolescence and the rate of return to an investment in a skill.

Occupational knowledge is cumulative and hierarchical in much the same way that mathematics and science is cumulative and hierarchical. Having good basic skills lowers the costs of developing occupational skills but it does not lower these costs to zero. Everyone must start at the bottom of the ladder of occupational knowledge and work their way up. New technology does require that workers learn new skills but the new skills are generally learned as small modifications of old skills. While learning a new skill is easier when the worker has good basic skills, a foundation of job knowledge and occupational skills is even more essential. New skills more of ten supplement old skills than supplant them. At some point every individual must start building his/her foundation of occupational skills. When the foundation building should begin is primarily a function of when the individual is able to decide which occupation to pursue. 
Skills and knowledge deteriorate from non use much more rapidly than they become obsolescent. In one set of studies, students tested 2 years after taking a course had forgotten $1 / 2$ of the college psychology and zoology, $1 / 3$ of the high school chemistry and $3 / 4$ of the college botany that had been learned (Pressey and Robinson, 1944). Kohn and Schooler, (1978) argue that even the very basic cognitive abilities tend to deteriorate if the worker's job does not call for their use. On the other hand, skills and knowledge that are used are not forgotten. In general, forgetting is a more serious threat to knowledge and skills than obsolescence. Consequently, when deciding what to study, the probability of using a skill or knowledge base is more important than the rate of obsolescence of that knowledge.

Occupational skills become obsolescent more rapidly than basic skills and this means that vocational teachers must give high priority to keeping their curriculum and their own skills up-to-date. But differences in rates of obsolescence are not decisive considerations in choosing between an academic and a vocational curriculum. Much more important is whether the knowledge and skills gained will be remembered and used. Basic skills are important to and used in almost all occupations and in most adult roles-parent, citizen and consumer --and, therefore, seldom deteriorate rapidly after leaving school. Basic skills, however, should not be confused with the content of specific academic courses. Much of this content is seldom used and quickly forgotten by those not going to college.

Since occupational skills are useful in a limited cluster of occupations, occupationally specific training needs to be conditioned on a reasonable prospect of soon working in the occupation. The reason for this conclusion is first, that the educational investment pays off only if the skills are used (see section 1); second, that skills deteriorate with lack of use; and finally that motivation to learn is weak if there is little prospect of using what is learned. Intensive occupationally specific training should begin after a student has made a reasonably well informed tentative career choice and be for occupations with good job prospects.

\section{PART II POLICY IMPLICATIONS}

High School vocational education has recently been subjected to some severe criticism. The Committee for Economic Development's blueprint for 
reform of public education Investing in Our Children, made the following statement:

"Unfortunately, whether measured by future earnings, job placement, or employment success there is today little evidence that vocational education is either meeting the needs of students or of the employers who are expected to hire them." (p. 30)

Some opinion leaders are arguing that occupationally specific programs should be phased out of high schools and concentrated in post-secondary institutions.

It is sometimes claimed that employers would then provide the training that schools do not, but no evidence for this proposition is provided. In the clerical field, for example, employers expect entry level employees to be able to type and often base their hiring selections on typing speed. If high schools stopped offering clerical training, students who did not want or could not afford to attend college would effectively be denied access to clerical occupations and a shortage of typists would soon result. When jobs requiring a great deal of on-the-job training are being filled, employers prefer recent high school graduates with vocational education in the field to high school graduates with no vocational training in the field (Bishop and Kang, 1988).

Furthermore, post-secondary vocational eduction is not without its problems: high dropout rates, unimpressive training related placement rates and in the proprietary sector very high default rates on student loans. Many students with serious basic skills deficiencies choose to pursue vocational programs. These deficiencies are not caused by vocational education, for they preexist entry into vocational courses and do not become worse during the final two years of high school (Bishop, 1985).

Who are vocational education students? Often they find academic learning difficult and their self esteem has suffered as a result. Often their friends denigrate the goals of schooling and encourage the use of drugs and alcohol. If something doesn't change, they may drop out. Occupationally specific education offers these students a new forum in which to try their talents; a forum in which success is possible and effort is rewarded. A good vocational program develops both vocational skills and a pride in these skills. Pride comes from succeeding at something that is difficult and that not everyone can do. Vocational clubs are examples of this philosophy in 
action. If dropout prone students are to be persuaded to stay in school, they must be offered an opportunity to develop pride and a route to something better than a job in a fast food job restaurant. To a large degree the holding power of vocational education derives from its promise of a better job.

How then can occupationally specific education organize itself so as to better deliver on this promise? The major implications of the research reviewed in part I of this paper is that the primary outcome of occupationally specific education is occupational knowledge and skills and that the benefits of this knowledge and skills derive from their use.

It is legitimate for vocational educators to focus on imparting occupational skills and knowledge, but they should not disclaim responsibility for whether the skills are used. The character of the programs influence whether students get a job or training opportunity that makes use of the skills and knowledge taught. Implicitly or explicitly, the students have been promised that if they try hard, they will benefit. The research implies that the benefits of occupationally specific education are primarily economic and that they derive from using the skills and knowledge gained (see section $1,2,4,5,6$ and 7 ). Consequently, programs need to be structured to maximize the probability that students get to use what they have learned either in a job or in further training.

The research discussed in section 3 , and 7 suggests how this may be accomplished: employers need to become more involved in planning and delivering vocational education, teachers and administrators need to give greater priority to the placement function, a well informed career choice needs to precede entry into intensive occupational training and programs need to be up to date and for occupations with strong employer demand. Strict new mandates regarding procedures for delivering vocational education are not desirable, however, for they are nearly impossible to enforce and are potentially counter productive because there is no single best method of serving students. What is needed most is the systematic collection of data on student outcomes and a funding system that prevents creaming yet rewards programs and teachers for achieving better student outcomes. 
State Funding Formulas

State governments pay a major share of the costs of vocational education and thus have a responsibility to see that this money is well spent. The effort to ensure quality by regulating the process by which vocational education is delivered has not been a success (Hoachlander, Choy and Lareau, 1985). It is well known that funding formulas have powerful effects on the behavior of local administrators. When devising these formulas it is important to give greater thought to their incentive effects.

The wrong incentives are generated by formulas for state reimbursement of the costs of occupational education that are based upon October enrollments or average daily attendance. The aid received by the district is unrelated to the effectiveness of its programs. Success in recruiting students into the program is rewarded rather than success in serving the student. Since the primary demonstrated benefits of vocational education are economic and derive from using the occupationally specific skills taught in school, it is appropriate for funding formulas to reward programs which do a better job of raising earnings of their graduates, of placing them in jobs or further schooling related to their training and of developing workers who are praised and appreciated by their employers. ${ }^{10}$ Since dropout prevention is another important benefit of vocational education, it is also appropriate for the formula to reward programs which lower the dropout rates of high risk students most dramatically.

State reimbursement formula should be based on outcomes not inputs and on students not programs. The formula should promote the revamping or discontinuation of programs that do not place a respectable number of graduates in jobs or further education related to the training, raise the earnings of program graduates above those of comparable nonvocational students or achieve some mix of well defined economic and educational goals.11

One of the concerns that has been expressed about performance standards is that it may encourage creaming. This can be avoided, however, by devising a formula that offers larger rewards for success in serving more challenging students: the learning disabled and those at high risk of dropping out. Since teachers quite naturally prefer to teach intelligent, well-behaved, motivated students, there will always be pressure to cream. ${ }^{2}$ Only powerful counter incentives can overcome the natural tendency to cream. State funding 
formulas can be such a counter incentive if they offer larger reimbursements for success with more challenging students -- the handicapped and those with poor marks in previous grades. If, for example, local districts received $\$ 3000$ for graduating and placing students scoring in the bottom quartile on standardized tests taken in ninth grade, but only $\$ 1000$ for graduating and placing students scoring in the top half of the test, a very powerful incentive would exist to seek out and serve the students for whom success is not assured.

The second feature of the proposed performance standards that would counteract existing incentives to cream is that reimbursement would not be based on the rate of the training related placement or on the average earnings gains, but rather on the number of training related placements or the average earnings gain times the number graduated. Teachers and counselors would thus face incentives to recruit/admit into vocational education all students who they feel they can help.

When outcomes like training related placements are part of the formula, adjustments would also need to be made for the intensity of demand in the local labor market. Since placements are more difficult to arrange when local unemployment rates are high, dollar reimbursements per placement should be higher when local unemployment rates are high. An illustrative formula that does this is given below:

$\mathbf{R}_{1}=\$ 1000-\$ 250($ JHSGPA $)-\$ 250\left(\right.$ Test $\mathrm{Z}$ score $\left._{1}\right)+\$ 100\left(\right.$ UnRt $\left._{1} 6\right)$

where $R_{1}=$ state reimbursement for the education of the $n_{1}{ }^{\text {th }}$ student, JHSGPA, is the "n"th students junior high GPA $\mathrm{Z}$ score (measured in standard deviations form the mean), Test $\mathrm{Z}$ score, $_{1}$ is the $\mathrm{Z}$ score on a comprehensive test of aptitude or achievement given in 9 th grade and UnRt is the local unemployment rate. ${ }^{13}$ Formulas should also be adjusted for fjelds of study to reflect differences in goals, costs of instruction, and market conditions (e.g., expected rates of training related placement might be higher for distributive education and for office education).

One potential objection to suggestions that funding allocations be based on success in training related placement is that the figures currently reported to state departments of vocational education are not comparable across districts and programs, are subject to manipulation and suffer from 
a nonresponse problem. However, there is no reason why a more reliable reporting system cannot be developed. Most states have a computerized wage reporting system for the 99 percent of all wage and salary workers that are covered by unemployment insurance. Estimates of the earnings impact of vocational rather than a general education can be obtained rather easily by merging wage record data into school files on curriculum and the test scores of students. Since the information system contains the name, address and industry of the student's employer, it can also be the starting point of a follow up system providing a valid count of graduates who have training related jobs. ${ }^{14}$

Rewarding the Teacher

The vocational teacher, not a placement director, should be responsible for placing his/her students. Mckinney et al., (1982) found that schools with placement officers actually had lower training related placement rates than schools which did not. Leaving the responsibility for placement with the vocational teacher forces more involvement with local employers and helps to foster a mentorship relationship between teacher and student. Teachers should assist their students, current graduates and past graduates to find training related jobs and their success in this area should be evaluated and rewarded.

Rewarding teachers for placing their graduates in a job or further schooling that is training related is appropriate because the necessary outreach work takes time and deserves compensation, and because an incentive to devote time to the task is necessary. Employer satisfaction with graduates, the wage levels of the jobs and the quality of teaching should also be evaluated and rewarded.

Counseling Before Entry into Occupationally Specific Programs

A great deal of counseling and thought should precede the student's choice of an occupationally specific program. Where possible and appropriate, career exploration courses should be available to 9th and 10th graders considering entry into occupationally specific training. Courses need to be specially designed with this purpose in mind. Skill instruction and hands on experience with the tools and materials of a craft are valuable but this needs to be supplemented by visits to work sites and the opportunity to 
interview and shadow workers in a variety of jobs in the field. High school labs and workshops do not by themselves provide a good preview of what a particular line of work is like.

An individualized employability plan should be developed jointly by school staff and students considering entry into occupational (as distinct from exploratory) vocational courses. For students considering an occupational specialty this process should include the following steps:

- disclosure of the past record of each vocational program in placing graduates in training related jobs or further education and the wages and other characteristics of the jobs obtained.

- student participation in a systematic career selection program.

- student investigation of the occupation through taking a part-time job or interviewing and shadowing people who work in the field. The student should be expected to write an essay about this experience and explain why he/she wants to prepare for this occupation.

- conferences with a guidance counselor on the issue of career choice and curriculum that include both the student and his parents.

- development of an employability plan for/with the student which would result in a "contract" being signed between students, parents, vocational teacher, the school and employer representatives. The student would state an intent to seek employment or further training in the field after graduating and teachers and employer representatives would assure the student of a training related job when the program is completed.

Programs with high placement rates and heavy demand should be expanded but where excess demand exists there is nothing wring with the common practice of giving preference to students who exhibit a particularly strong commitment to the occupation. ${ }^{15}$ Motivation and grades in courses that prepare one for the field might also be considered. Even where everyone who applied is admitted, it is desireable to project an image of selectivity because it prevents vocational students from being stigmatized and instills pride in the chosen field and a commitment to excel.

Screening students for interest might initially reduce the number of students in occupationally specific educational programs. But if it succeeds 
in raising the esprit of the students in occupational programs and the payoff to their training, the high standards can be expected to attract additional students into the field just as they have been attracted to the magnet high schools of New York, Chicago and many other cities.

\section{Summary and Conclusions}

Until new evidence of unique educational effects of rocational education is produced, the primary justification of occupationally specific education must remain an economic one. It must make the students better off economically: either by increasing the probability of graduating or improving employment chances after graduating. Making the vocational students no worse off is not good enough. If the economic effects of taking academic and occupational courses in school were equal, the public would probably want to substitute academic for occupational course work. Their preference for the academic has a rational base:

- academic courses are less costly to teach (because class sizes are larger and space and equipment needs smaller)

- employers expect to teach occupational skills to new hires who have not received training in high school but they are unlikely to teach the material covered in academic courses.

- academic course work is better preparation for college than occupational course work so choosing an occupational curriculum inevitably reduces the ability of the student to choose to attend a 4 year college.

o the public's educational goals are in part cultural and political and nonvocational courses make greater contributions to these goals.

- occupational skills become obsolescent more rapidly than basic skills.

Raising the proportion of graduates who use the occupational skills taught needs to receive very high priority. Teachers and programs need to be evaluated on the basis of the number of graduates who get a job or continue their education in the field. Employers should become more involved in delivering occupational training. Teachers should no longer be sole instructors for occupation specific skills. Where feasible coop employers might become the primary instructors for these skills. The teacher's role 
would become one of mentor and facilitator of learning and job placement, and the role would not terminate when the student graduates. Much more would be expected of vocational teachers, so it would probably be necessary to increase the teacher-student ratio. New funds would need to be committed to vocational education but the extra money should be distributed as rewards for results --not as reimbursement for increased expenses. State mandated procedural requirements seldom work. Local administrators and teachers inevitably have the ultimate responsibility. The resources for implementing reform should come from a generous performance based funding formula. 


\section{FOOTNOTES}

1. The occupation of the current or most recent job is matched against field of training to define training relatedness. One has to be in the labor force at least one week during the year to be in a training related job, so the association between the two reflects both directions of causation. Since almost all individuals in the sample had been in at least one job since completing school, this is not likely to be a serious source of bias.

2. All published estimates of the impacts of vocational education (including the estimates of the impact of vocational education that results in a training related job) are potentially subject to selection bias. Even though these estimates are made while controlling for all measurable background characteristics, it is possible that there is some unmeasured personality trait that (a) existed prior to entry into vocational education (b) is stable and (c) has important effects on both the outcomes studied and the probability of participation in vocational education or of finding a training related job. We could, of course, be more confident of our estimates of the impacts of vocational education if they were based on an experimental design, but in the absence of such experiments policy decisions must be based on the high quality nonexperimental longitudinal studies that are available. Selection bias probably exaggerates the effect of training relatedness for unemployment and wage rates. Error in the measurement of training relatedness has the opposite effect. When workers who in fact have a training related job are misclassified as working in an unrelated field, the estimated effect of training relatedness on wages and unemployment will be biased toward zero.

3. The analysis makes use of data on 550 pairs of recently hired workers employed in the same or a very similar job at 550 different firms. The following model was estimated:

$$
Y_{1}-Y_{2}=A\left(D_{1}-D_{2}\right)+B\left(X_{1}-X_{2}\right)
$$

where $Y_{1}-Y_{2}=$ is the difference between the productivity or required training of person 1 and person 2

$D_{1}, D_{2}=A$ dummy indicating that person 1 or 2 had obtained vocational training from a school that was relevant to the job for which he/she was hired

$\mathrm{X}_{1}, \mathrm{X}_{2}=\mathrm{A}$ vector of control variables for the circumstances of the hire, and the new hires other credentials. When current productivity is $Y$, tenure squared are included in the $X^{\prime} s$.

4. When a less rigorous definition of training relatedness is used (e.g. one based on questions like "On your present job, how much do you use the vocational training you received in high school or area vocational center?" Bice and Brown, 1973), more than half of vocational graduates report using their training. This implies that a substantial minority of vocational graduates report making some use of their vocational 
education even though there is no match between their occupation and their training. The Campbell et al., (1986) study implies that the amount of carryover is probably quite small, for these graduates were treated as having an unrelated job and the overall wage impact of vocational education for those with an unrelated job was close to zero.

5. The U.S. rate of training related placement might have been somewhat higher if measured 6 months after high school graduation. However the German definitions of relatedness are more rigorous and applying them to U.S. data would have lowered training related placement rates. High unemployment rates no doubt contribute to the low rates of training related placement in the U.S. However, aggregate differential between the countries in training related placement cannot be attributed to differentials in the general tightness of labor markets.

6. The study derived a 4 factor representation of job satisfaction from a factor analysis of a battery of the job satisfaction questions in the NLS youth data base and then analyzed the effects of vocational education in high school on these 4 dimensions of job satisfaction. Neither taking vocational courses nor finding a training related job appeared to have a significant impact on job satisfaction. Two years of data were studied and 3 modes of participation and 4 kinds of job satisfaction were defined so the hypothesis that vocational education improves job satisfaction was tested 24 different times. Only two of these coefficients were statistically significant at the .05 level, barely more than what would be expected by chance. Only one of the eight coefficients testing the impact of having a training related job was statistically significant (Campbell et al., 1982, Appendix tables E-1 to E-4).

7. Most of the research used supervisory ratings as the criterion of performance but the basic finding is, in fact, strengthened when better work sample measures of performance are employed. (Hunter, 1983)

8. These test validities are calculated by dividing observed correlations between the tests and supervisor reports of job performance by the known reliabilities of the tests and the criterion.

9. If students are able to evaluate program quality and avoid programs judged of low quality, enrollment based funding will reward quality. Students, however, are not well informed about program quality, they may not care about quality and their commitment to a particular occupation may be so strong they will stick with it even if the teacher is doing a poor job. An additional problem is that student enrollment choices may be manipulated by teachers with quotas to fill. Especially perverse incentives arise when occupational programs must have some minimum enrollment to receive state funds. Teachers in need of bodies to meet the target are often willing to accept and sometimes actively recruit into their program students who they know do not want or have only a low probability of getting a job in the field.

10. The use of training related placement rates in reimbursement formulas is clearly feasible for it has been implemented in two states, Florida 
and South Caroline. JTPA's performance standards also have many similarities to what is being proposed here. Tennessee funds it's state colleges and universities in part through a performance incentive system (Bogue \& Brown, 1982).

11. The outcomes included in the formula would not have to be limited to economic outcomes. Other indicators might also be employed such as: checklists of competencies attained, numbers of participants in skill olympics and the average rating of the submissions, completions of more advanced training by program graduates, evaluations by the teachers in these postsecondary programs, and scores on occupational competency exams or state licensing exams.

12. Reputations of teachers and programs are influenced by absolute levels of student performance -- contests won, houses well constmucted, and good jobs obtained. Value added -- saving students who were headed for failure -- is much harder to assess. Attention goes to the students who fail rather than the ones who graduate and find a job despite handicaps or a disadvantaged background. Not surprisingly teachers compete for the opportunity to teach the better students. All of these factors create incentives to cream -- that is to recruit the most able and screen out those with learning problems or a bad attitude.

13. The selection of specific parameters for such a formula is a political decision because distributional considerations must be balanced against incentive effects. Each criterion used would need its own set of adjustment factors. Studies of the background and environmental determinants of each potential criterion would be helpful in making these decisions but are not necessary. Performance based funding formulas are feasible for general education as well.

14. In many cases the match between the industry and the field of training will be so close that a training related placement can be assumed without the necessity of a follow up. Where the nature of the job is not clear from the industry code, a card could be sent to the employer requesting a description of the employee's job and possibly also asking for an evaluation of the training the employee had received. If no response is received from the card, an independent survey firm could be contracted to telephone the employer. Where no match turned up in the system, an effort could be made to call the student's parents. The list of students and their job classifications would be sent to the vocational teacher and the school district. This would give the teacher the opportunity to appeal and correct mis-classifications.

15. Students who have not signed a contract and who do not have career plans in the field might be allowed to take vocational courses along side of the "contract" students but state reimbursements would not be available for such students. 


\section{REFERENCES}

Bice, Garry R., and Brown, Ralph. Selected Information and VocationalTechnical Education in Tennessee for the School Year 1972-73, Information Series No. 20. Nashville, TN: Tennessee State Department of Education, Division of Vocational-Technical Education. Tennessee University Knoxville, Occupational Research and Development Coordinating Unit, 1973. ED 091516 CE 001283.

Bishop, John. The Social Payoff for Occupationally Specific Training: The Employers' Point of View. Columbus: The National Center for Research in Vocational Education, The Ohio State University, November, 1982.

Bishop, John. Preparing Youth for Employment, Columbus: The National Center for Research in Vocational Education, The Ohio State University, 1985.

Bishop, John and Kang, Suk. "A Signaling/Bonding Model of Employer Finance of General Training." Center for Advanced Human Resource Studies Working Paper \# 88-08, Cornell University, Ithaca, New York, 1988.

Bogue, Grady E. and Brown, Wayne. "Performance Incentives for State Colleges." Harvard Business Review, November-December, 1982.

Campbell, Paul B.; Elliot, Jack; Hotchkiss, Larry; Laughlin, Suzanne and Seusy, Ellen. "Antecedents of Training-Related Placement."

Columbus: The National Center for Research in Vocational Education, The Ohio State University, 1987a.

Campbell, Paul B.; Elliot, Jack; Laughlin, Suzanne and Seusy, Ellen. "The Dynamics of Vocational Education Effects on Labor Market Outcomes." Columbus: The National Center for Research in Vocational Education, The Ohio State University, $1987 \mathrm{~b}$.

Campbell, Paul B., and Basinger, Karen S. "Economic and Noneconomic Effects of Alternative Transitions Through School To Work." Columbus: The National Center for Research in Vocational Education, The Ohio State University, 1985.

Campbell, Paul B.; Basinger, Karen S.; Dauner, Mary Beth; and Parks, Marie A. "Outcomes of Vocational Education for Women, Minorities, the Handicapped, and the Poor." Columbus: The National Center for Research in Vocational Education, The Ohio State University, 1986.

Campbell, Paul B.; Mertens, Donna M.; Seitz, Patricia and Cox, Sterling. "Job Satisfaction--Antecedents and Associations." Columbus: The National Center for Research in Vocational Education, The Ohio State University, 1982 .

Campbell, Paul B.; Orth, Mollie N.; and Seitz, Patricis. Patterns of Participation in Secondary Vocational Education. Columbus: The National Center for Research in Vocational Education, The Ohio State University, 1981 . 
Conroy, William G., Jr., and Diamond, Daniel E. The Impact of Secondary School Occupational Education in Massachusetts. Lowell, MA: University of Lowell, College of Management Science, Sprint 1976. ED 122095.

Daymont, T. N., and Rumberger, R. W. "The Impact of High School Curriculum on the Earnings and Employzbility of Youth." In Job Training for Youth, edited by R. Taylor, H. Rosen, and F. Pratzner. Columbus: The National Center for Research in Vocational Education, The Ohio State University, 1982 .

Federal Institute for Vocational Training. "The Transition of Young People into Employment after Completion of Apprenticeship in the 'Dual System'." West Germany: The Federal Institute for Vocational Training, 1986.

Felstehausen, Joyce L., et al. Follow-Up Report on mlinois "Class of 71" Occupational Program Alumni, Final Report. Charleston: Eastern Illinois University, Center for Educational Studies, June 1973. ED 087866.

Gustman, Alan L., and Steinmeier, Thomas L. "The Relation Between Vocational Training in High School and Economic Outcomes." Paper prepared for the Division of Technical Systems in the Office of Technical and Analytic Systems, Office of the Assistant Secretary for Planning and Budget, U.S. Department of Education. Hanover, NH: Darthmouth College, July, 1981 .

Hoachlander, E. Gareth; Choy, Susan P.,; and Lareau, Annette P. "From Prescriptive to Permissive Planning: New Directions for Vocational Education Policy." MPR Associates, Inc. Berkeley, California, September 1985.

Hunter, J.E. "Causal Analysis, Cognitive Ability, Job Knowledge, Job Performance, and Supervisor Ratings." In Performance Measure and Theory, edited by S. Lundy, F. Zedeck, and S. Cleveland. Hillsdale, NJ: Lawrence Erlbaum, 1983.

Hunter, J.E., and Hunter, R. F. "The Validity and Utility of Alternative Predictors of Job Performance." Psychological Bulletin, 96, no. 1 (1984): 72-98.

Kohn, Melvin, and Schooler, Carmi. "The Reciprocal Effects of Substantive Complexity of Work and Intellectual Flexibility: A Longitudinal Assessment, American Journal of Sociology, 1978.

Levin, Henry, and Rumberger, Russell. "The Low-Skill Future of High Tech." Technology Review, August/September 1983 special report.

Lorge, I. "Schooling Makes a Difference." Teachers College Record 46 (1945): 483-492. 
Mangum, Steve, and Ball, David. "Military Service, Occupational Training and Labor Market Outcomes: An Update." Columbus: Center for Human Resource Research, The Ohio State University, March, 1886.

Mayfield, E. C. "The Selection Interview: A reevaluation of Published Research." Personnel Psychology 17 (1964): 239-260.

Mertens, Donna M.; McElwain, Douglas; Garcia, Conzalo and Whitmore, Mark. "The Effects of Participating In Vocational Education: Summary of Studies Reported Since 1968." Columbus: The National Center for Research in Vocational Education, The Ohio State University, May 1980.

Mertens, Donna M.; Seitz, Patricia and Cox, Sterling. "Vocational Education and The High School Dropout." Columbus: The National Center for Research in Vocational Education, The Ohio State University, September 1982.

Meyer, R. "Job Training in the Schools." In Job Training for Youth, edited by $R$. Taylor, H. Rosen, and F. Pratzner. Columbus: The National Center for Research in Vocational Education, The Ohio State University, 1982.

Meyer, Robert. "Vocational Education: How Should It be Measured?" Cambridge, MA: Urban Institute, Harvard University, 1981.

National Commission for Employment Policy. "The Federal Role In Vocational Education." August 24, 1981.

Plisko, Valena White (ed.). The Condition of Education. Washington, DC: National Center for Education Statistics, U.S. Department of Education, 1984 .

Pressey, Sidney, and Robinson, Francis. Psychology and New Education. (New York, Harper and Brothers Publication, 1944), p. 544.

Reilly, R. R., and Chao, G.T. "Validity and Fairness of Some Alternative Employee Selection Procedures." Personnel Psychology, 35 (1982): 162.

Schmidt, Frank L., and Hunter, John E. "Individual Differences in Productivity: An Empirical Test of Estimates Derived from Studies of Selection Procedure Utility." Journal of Applied Psychology, 68, no. 3 (1983): 407-414.

Silberman, Harry F. "Problems of Cooperation and Coordination in Vocational Education." Chapter Xii, Education and Work: 1982. Eighty first Yearbook of the National Society for the Study of Education. 